\title{
THE STUDY OF ENGLISH LITERATURE
}

\author{
Ista Maharsi \\ Universitas Islam Indonesia
}

\begin{abstract}
Learning English language and English literature seems to bring about considerable questions of the benefits and the importance of so doing. Why should students who learn English language require learning English literature at the same time? The ultimate matter remains the samewhat is the very core of learning the subject? What do their relationships embrace? What, why, and how are we supposed to know that?
\end{abstract}

Keywords: English language, English literature

\section{INTRODUCTION}

As is known, English Studies may comprise of English Linguistics, English Teaching and English Literature. These three studies are the logical next step of efforts to acquire skills in understanding and using English, particularly for those who aspire to broaden and deepen their knowledge and mastery of English. Therefore, an acceptable degree of English mastery is required to study English literature, for example. The higher one's mastery of English the stronger is one's English sense and hence more sensitive is one's knowledge and critical awareness about English literature. More than that, this paper argues that English language and English literature are in fact inseparable with one needing the other.

However, the study of English literature is more than just English. It is about nearly all facets of society lives from which the English literary works spring up. That is, English-speaking people of certain country, academic, working, religious, and cultural backgrounds and political leanings and of certain times express various aspects of their lives in written English. The main objectives of studying their literary works are to enrich our knowledge and understanding of the 
high values of morality and wisdom they contain. However, to know what an English literary work is all about and the messages it wants to convey requires "know-how" that include English skill and strategies. Therefore, this paper argues that the study of English literature can only occur with the presence of the whywhat-how balance. The sections to follow explain those arguments.

\section{LANGUAGE AND LITERATURE: UNSEPARATED MATES}

There are many definitions of language comprehensive, deep, or simple ones. According to Chomsky, language is "a set (finite or infinite) of sentences, each finite in length and constructed out of a finite set of elements" (1957, p. 13). In Merriam Webster dictionary, language is defined as system of conventional spoken or written symbols used by people in a shared culture to communicate with each other. A language both reflects and affects a culture's way of thinking.... In comparison, Oxford dictionary defines language as "the method of human communication, either spoken or written, consisting of the use of words in a structured and conventional way." From that of Chomsky to the more recent definition of language, the essence remains the same. Language contains rules and elements, takes both spoken or written form, reflects the speakers' culture and way of thinking, and it is significantly used to communicate ideas.

Literature, in fact, does not have less meaning than language. According to Widdowson, literature has various meanings depending on the context that the speakers refer to. It may mean literary writings such as fictions or literature in term of major of study. Literature referring to literary writing could be defined as "the achievement of aesthetic and moral merit" such as those of canon or the great tradition. Or else, it is understood as the "creative and imaginative" writing (1999, p. 4-5). Merriam Webster illustrates literature as "writings having excellence of form or expression and expressing ideas of permanent or universal interest" and Oxford terms literature as "written works, especially those considered of superior or lasting artistic merit." Literature has the so called a range of characteristics such as excellent, aesthetic, creative, imaginative, expressive, valuable, and universal. Therefore, in delivering its characteristics and entity, a toollanguageis unavoidably necessary. It becomes the only choice and its ultimate means.

Now that definitions of both language and literature have been set, their relations are consequently visible. In the digital world glossary, it can be termed 
that literature is the message, language is the mobile phone. Those two relationships are closely bound and would not be separated in whatsoever ways. The proximity makes them mates and this idea underlies the symbiosis of both of them, regardless the facts that there are debates as to how far a learner needs to study both of them.

In kindergarten, primary and secondary schools, the study of literature is not the major study. It is the minor subject that helps the students get exposure to aesthetic, creative, and imaginative writing. Although not a major study, literary writing such as stories, poetry, and drama are well told, memorized, and played. In our childhood days, bedtime stories are our lullabies to have beautiful dreams and dramas are our proud proof of existence on the elementary and secondary stages. One or two of the children stories told by our grandmothers, grandfathers, fathers, or mothers are clearly or unclearly remembered.

In higher schools, literature, from the simplest form to the hardest, can be a learning material for students. Wide ranges of literary work from the canon to the contemporary form of literature are available for learning. Plays, that commonly use more simple language, can be one of discussion topics in a language classroom. It can be aimed to expose students to colloquial language in which students can adapt and adopt the expressions and later on use the expressions in particular contexts. Novels, which are of more complicated language style, contents, and topics, can be used in advanced language classroom in order to give more complex language exposure to students. This, therefore, is expected to enhance students' language experience which in turn affects their language competence. All the above practices are indeed an early yet subtle introduction to literature. This simply shows that literature has filled our lives since we are at the early stage of life and it must have been carried on and has either huge or little impact on the present life.

Language and literature are two closely related subjects that need each other. To learn English literature, for example, needs mastering English and to master English needs studying English literature. This is because English language serves as a tool in studying English literature, without which the study is impossible. There is no way to understand an English literary work when little is known about, for instance, how a sentence is constructed and how a sentence can have lexical and connotation meanings. Therefore, a good command of English is a prerequisite for studying English literature. Only with a certain level of English skill is it possible for someone to endeavor the English literature study. 
Similarly, the mastery of English can be enhanced and perfected by studying English literature. Although the main objectives of reading English literary works are to enrich one's knowledge and understanding and to empower oneself, no doubt it also improves one's skill in using English. A frequent reading of English novels and short stories, for example, likely develops and strengthens one's language sense as to how the dialogues between characters, the setting description and the psychological mood of the characters are written. Likewise, a constant reading of English history works familiarizes one with how chronologies are composed in English. Another important boost of English skill resulting from intense readings of English literary works is undoubtedly the awareness of close relationship between text and context. That is, certain English texts are used to depict certain contexts. Conversely, certain contexts are described with certain texts not others. Therefore, if one wants to be able to write a good journalistic report, for example, one must frequently read journalistic works.

\section{THREE FOUNDATIONS OF “WHY-WHAT-HOW" IN THE STUDY OF ENGLISH LITERATURE}

The study of English literature can only occur with the presence of the whywhat-how balance. Why do people need to learn English Literature? People will not study English literature unless it entails benefits. What benefits does English literature give to the reader? Many literary works have high values of morality and wisdom lessons in many different places at different times. Any writings or texts that function to enrich our knowledge and our understanding and empower our selves are essential. There is always a belief that any literary works will certainly give certain meanings to a certain people. People learn particular things from particular sources and thus they have the capacity to give values to any works that are considered precious. Further, the value embedded in a literary work is given by anyone who reads and responds to it based on their own experiences, purposes, and interpretation.

In addition, as far as English literature is concerned, there is language and power issue. Who rules the world seems to be the one with English as their first language. Although nowadays the distinction between English as the first, second or third is hard to tell, the central power still looks the same. This means that English language mastery that may result from studying English literature is a precondition to gain power. 
However, we cannot learn the lessons and capture the massages from an English literary works unless we know what it is all about. It is about nearly all facets of society lives from which the English literary works spring up. That is, English-speaking people of certain country, academic, working, religious, and cultural backgrounds and political leanings and of certain times express various aspects of their lives in written English. Brumfit (2001) argues "a successful reading of a work of literature is an act of interpretation, in a context where taste and style is often highly valued and where inexperienced learners face an enormous temptation to rely on secondary understanding..." (p. 94). Literature needs to be analyzed through the interrelationship between text and context in order to establish and synthesize meanings and appreciation to the work. The inherent relationships between the text and context, consequently, provide more values to the work. Furthermore, extensive ways to interpret a literary work have resulted in a rich critical analysis combining interdisciplinary knowledge such as sociology, psychology and history. Indeed, it is enrichment beyond literature as a text.

Further, the study of English Literature takes literature as its object of study. Brumfit (2001) affirms that literature itself contains many aspects that are supposed to be learnt, such as knowledge, attitudes, skills and responses. The knowledge of English Literature may include the English literary tradition, genre, western culture, local context, and analysis of literary texts in detail. Additionally, the attitudes towards English literature should cover the tolerance, respect and understanding on cultural, imaginative and intellectual differences. In addition, literary criticism, as the result of critical thinking and creative interpretation, is among the skills needed in learning English Literature. On the one hand, literary criticism seems to be a 'correction' or 'positive-negative appreciation'. On the other hand, literary criticism is, in fact, a contribution and an enhancement to the world of literature. It shows how a literary work is gaining much deeper and extended meaning in and through other people's viewpoint and reaction and thus leads us to find wisdom in our lives.

To understand all these requires "know-how" or methods. According to Richards and Rogers (2001) methods include approach, design and procedure. Although Richards and Rogers' theory concerns with language teaching, it also seems to apply in learning English Literature. In approach, for example, a theory of the nature of literature and the nature of literature learning, without which it may be impossible to get the ideas of literature learning, should be well discerned. The nature of literature, particularly, lays in the literary work's embedded values 
(Brumfit, 2001). Whether or not a literary can be used in a wider perspective and thus it is worthy, determines its category.

Methods, strategies and techniques used in the study of English literature need to adjust to individual purposes of studies. A close reading of a literary work through language analysis might be a good start. Yet, in order to know how to relate and investigate a literary work, learners need to understand the background of the writer, the society in which the work is made, and the author's personal experience with the work. They also need what kinds of approaches that need to be applied to analyze a literary work.

In addition, the procedure of learning English literature includes time allocation and equipment availability such as media or multi-media laboratory. It will be much more interesting to learn poems through poems reading and learn a film in a laboratory. The next step to analyze a poem is knowing how to understand each word both lexically and connotatively. Diction, word arrangement, rhymes, grammatical and syntactical analyses are of necessary information to be discussed. Indeed, language becomes the only means to examine poems.

Now that we are living in the Post Modern era, methods, strategies and techniques used in learning English Literature are also influenced by it. The awakening of Post Modernism, Feminism and Post Colonialism have given rise to the more universal and flexible approaches to studying English Literature. The "grand narratives" is no longer considered as possessing the highest truth or the absolute truth. The Post Modern Era gives more freedom and self-values of literary works (Widdowson, 1999, p. 87). In short, approaches to understand literature has given great chance to reveal various values and truth embedded in literary works.

In a learning process as well as teaching process, skills, methods and strategies are used as ways to acquire knowledge. Without them, the learningteaching process will be unorganized and incoherent. In English Literature, for example, the knowledge of genre appears to be significant starting points before analyzing poetry, prose or plays. Before reading Nathaniel Hawthorne's Scarlet Letter, for instance, the knowledge of genre will significantly help the reader in understanding the novel. The reader will be given clues on the expected conflicts that might happen in the story, the complexity of plots and characterization.

Jumping ahead to more recent use and advancement of technology in classrooms across the globe, teachers and lecturers are deemed responsible for adjustment and empowerment. Bringing have-just-read old yellow classical 
novels into classrooms and conducting a comparison study of the movie version of the same title would be challenging and probably astonishing. Drawing red lines between the canon and the technologically adapted stories would be another great experience. LoMonico proposes an idea of "singing out Whitman's "Song of Myself" and then write and recite our own version." Rather than reading Shakespeare's plays, acting like Shakespeare himself, making a newspaper board of the news collection during the Elizabethan period from the internet, and replicating or redesigning clothes that they wore would be of exciting projects to have (n.d). Shifting methods and strategies would not undermine the literary works only when it is well-planned and designed. Variation would enhance the study of literature and cherish the learning environment.

The new shift in the language study, from single to multiple viewpoints, has been regarded as the most effective and appropriate method to be implemented. Likewise, the study of literature also offers more freedom of interpretation and appreciation. Learners are not the passive agents anymore; rather they are encouraged to initiate research on literature based on their own interest. Therefore, they are expected to empower themselves with the values they get from literature which are relevant with their lives.

\section{CONCLUSION}

In fact, the presence of the why-what-how balance is required in learning any subject. While the "know-why" aspect gives the ideas of the importance of and background of such a learning, the "know-what" aspect limits the scope of the object of learning. Further, the "know-how" aspect explains the way in which a learning process could be conducted.

There could be at least three reasons that there should be balance between the 'know-why', 'know-what' and 'know how'. Firstly, Learning English Literature is a construct in the whole body of learning. Since it is a construct, it should have a system. The system, in this case, serves as the correlation and interrelationship between each part. Thus, the "know why-what-how" are elaborated in order to build a scientific reasoning through observation, discussion and practices. Learners are best given more chances to explore and express their understanding of a literary work through short papers or essays. Secondly, since the study of English Literature is also meant to develop positive values embedded in a literary work in 
order to acquire critical thinking, the syllabus should be designed to support learners to discover knowledge. The materials that are going to be discussed should 